PROCEEDINGS OF THE WORLD BANK ANNUAL CONFERENCE

FILE COPY'

\title{
Incentives for Small Families: Concepts and Issues
}

\author{
Kenneth M. Chomitz and Nancy Birdsall
}

\begin{abstract}
This paper examines the benefits and costs of client-targeted family planning incentives-public policies providing specified rewards or penalties for specified fertility-related behavior. Two rationales for incentives are discussed: first, where markets for contraceptives or contraceptive information fail, incentives can increase families' welfare by reducing barriers to the use of contraception; and, second, where childbearing imposes external costs not borne by parents, incentives can align private and social costs, improving social welfare. These distinct rationales require distinct types of incentives. Incentive costs include economic costs of program administration; the fiscal (but not economic) cost of the incentive payments; welfare losses incurred if ill-informed or myopic individuals make choices they later regret. Little has been done to assess the costs and benefits of existing or proposed incentive schemes. A framework for doing so is presented. Preliminary evidence from an experiment in the state of Tamil Nadu in India suggests that incentives for short-term trial of contraceptives or for acquiring information may offer substantial benefits at low cost.
\end{abstract}

The use of incentives to encourage small family size has evoked strong emotional reactions. In this paper we take an analytic view of this value-laden subject. In doing so, we use the simple analytics of welfare economics, in which public policy must be justified as enhancing overall social welfare; and in which trade-offs between the welfare of different individuals, and between individuals and society as a whole, are carefully evaluated.

We define incentives as public schemes or policies that provide specified rewards (or penalties; that is, disincentives) for specified fertility-related behavior. Although most family planning programs do not employ such policies, incentives have been used on a massive scale by many governments over the last

Kenneth M. Chomitz is assistant professor of economics at Boston University. Nancy Birdsall is chief of the Environment Division of the Latin America and the Caribbean Technical Department at the World Bank. The authors are grateful to Janice and Carl Stevens for valuable discussions; to Jere R. Behrman for useful comments on an earlier draft; to seminar participants at Harvard University and the World Bank; to Christine Evans for research assistance; and to Professor R. Subramanian, head of the Department of Applied Research, and his colleagues at the Gandhigram Rural Institute for making available data from their Ammanpettai Survey.

(C) 1991 The International Bank for Reconstruction and Development / THE wORLD BANK. 


\section{Fertility Policy and Market Failures}

In developing countries, public policies to affect fertility choices of individuals are generally justified on two grounds. One is the presence of externalities associated with childbearing, so that people have higher fertility than is socially optimal, because they do not incur the full costs of children themselves. ${ }^{3}$ The second is failure in the markets for contraceptive information and services, so that people have higher fertility than they would choose were they betterinformed about contraceptive options or better provided with services (see, for example, National Research Council 1986; and Birdsall 1989).

The single most common public intervention to affect fertility in developing countries is the subsidization of voluntary family planning services. ${ }^{4}$ Such subsidies are widely viewed as simultaneously addressing both types of market failures. First, to the extent that lower costs of contraception lead couples to voluntarily reduce their own fertility, aggregate fertility falls, and any negative externalities associated with childbearing are reduced. Second, by filling in for missing private markets, public family planning programs reduce the financial, health, and psychic costs of contraception. This directly increases couples' welfare by providing them with a wider range of choice about family size and expenditure. ${ }^{5}$

Thus, to the extent that there are any negative externalities to childbearing, contraceptive information and services reduce those externalities without imposing any costs on individuals. In fact, they yield direct benefits for individuals.

Increases in education, reductions in infant mortality, improvements in the status of women, and other changes in the environment that affect individuals' demand for children are also widely discussed as interventions that governments may use in the presence of externalities to alter individual fertility behavior (see World Bank 1984). For example, women's education is hypothesized to reduce fertility by raising the opportunity cost of children to women. Like public sup-

3. Externalities imply a cost or benefit that markets do not reflect. For instance, your decision to burn gasoline may not take account of the cost imposed on everyone else by the resultant smog. But if that cost can be quantified and then directly imposed on you via a gasoline tax, your consumption will be reduced to the socially optimal level.

4. These may take the form of direct provision by the public sector of contraception, often at zero price to consumers, or of public subsidies to nonprofit and for-profit providers. Subsidizing private sector provision is referred to as contraceptive social marketing (see Behrman 1989).

5. Put another way, with lower costs of using contraception, individuals are better off, either because they avoid so-called unwanted fertility or because they achieve their desired fertility at lower cost. Becker and Lewis (1973) and Easterlin and Crimmins (1985) also point out that lower contraceptive costs may actually change the underlying demand for children, reducing the level of fertility that a couple views as optimal. In the Becker and Lewis model, a change in the price of contraception reduces the optimal number of children by affecting the trade-off between quality and quantity in the budget constraint; the higher price of quantity implied by lower contraceptive costs reduces the relative price of quality of children, raising demand for quality relative to quantity. In the Easterlin and Crimmins model, the optimal number of children is itself a function of the disutility of using contraception, at least for couples whose potential fecundity exceeds their (initial) desired number of children. 
port for family planning, these environmental changes are viewed as benign policies because they reduce fertility at the same time as they provide direct benefits to individuals.

Incentives to reduce fertility, like public subsidies for family planning, can be justified on the grounds that they correct for market failures in the provision of contraceptive information and services. Moreover, like policies to increase women's education, they can be justified on the grounds that they reduce the demand for children by raising the cost of children, correcting for social externalities of high fertility. In the next section we discuss two broad categories of incentives corresponding to these two major classes of market failure.

\section{Market Failures and Incentive Designs}

Table 1 summarizes our typology of incentives based on the market failure or other problem incentives can address; the implications of each market failure for the design of incentives; and the implications for policy alternatives other than incentives.

\section{Barriers to the Use of Contraception}

A number of market failures and related problems create barriers to the optimal use of contraception from an individual's or a couple's point of view.

Table 1. Market Failures and Incentive Design

\begin{tabular}{|c|c|c|}
\hline Failure & $\begin{array}{l}\text { Implication for } \\
\text { incentive design }\end{array}$ & Alternatives to incentives \\
\hline \multicolumn{3}{|c|}{ Barriers to the use of contraception. } \\
\hline $\begin{array}{l}\text { Poor information; high cost } \\
\text { of information }\end{array}$ & $\begin{array}{l}\text { Small payments for limited } \\
\text { time; verification of } \\
\text { contraceptive use not } \\
\text { needed }\end{array}$ & $\begin{array}{l}\text { Expand services; } \\
\text { fieldworkers; community- } \\
\text { based distribution; } \\
\text { information, education, } \\
\text { communication (IEC) }\end{array}$ \\
\hline High costs of early adoption & $\begin{array}{l}\text { Payments where prevalence } \\
\text { low; verification not } \\
\text { necessary }\end{array}$ & Same as above \\
\hline Procrastination; myopia & $\begin{array}{l}\text { Payment tied to perceived } \\
\text { adoption costs; payments } \\
\text { for trial adoption }\end{array}$ & $\begin{array}{l}\text { Same as above; upgrade clinic } \\
\text { services }\end{array}$ \\
\hline Lack of credit market & Payment tied to adoption costs & $\begin{array}{l}\text { More widespread services to } \\
\text { reduce financial costs to } \\
\text { individuals }\end{array}$ \\
\hline Lack of insurance market & $\begin{array}{l}\text { Payment contingent on high } \\
\text { losses }\end{array}$ & $\begin{array}{l}\text { Improve credit and insurance } \\
\text { markets }\end{array}$ \\
\hline \multicolumn{3}{|c|}{ Gap between private and social costs and benefits } \\
\hline Externalities & $\begin{array}{l}\text { Deferred payments } \\
\text { Possibly larger payments } \\
\text { Verification critical }\end{array}$ & $\begin{array}{l}\text { Change environment } \\
\text { (education, health, and } \\
\text { so on) } \\
\text { More family planning } \\
\text { Tax children-but see text } \\
\text { Quotas--but see text }\end{array}$ \\
\hline
\end{tabular}


Failure in the market for information. Because information is to some extent a public good, private providers are not likely to supply it in adequate amounts. This is particularly the case when information (for example, about the possibility of controlling fertility) cannot easily be tied to a specific marketable product. Thus, information about rhythm and withdrawal has no private market, nor does information about the pill in rural areas where there is no real market for private medical services. Yet the welfare gains to individuals from accurate information of this kind may exceed the costs of providing that information.

Demand for information may also be suboptimal. The collection and evaluation of information is costly, particularly for less-educated consumers and for more complex products. Consumers may therefore rationally screen out information whose expected worth is less than the costs of evaluation. They will therefore sometimes fail to acquire information that is actually worthwhile.

This problem of suboptimal demand for information may be particularly severe in the context of family planning where the product is a complex set of ideas and procedures whose benefits are not immediately apparent but whose perceived risks may be high. In addition, much information-for example, regarding appropriate method and medical contraindications-is client-specific and may be too sensitive and complex for the mass media to convey.

To penetrate this information screen, family planning programs sponsor domiciliary visits by fieldworkers as an adjunct to mass media advertising. But in some settings, it may be cheaper to pay for a potential client's attention-for example, to pay him or her to visit a clinic and attend an educational presentation-than to disseminate information via fieldworkers. This device, familiar to developed-country consumers of automobiles and real estate, has also been used with some success in the Gambia to teach mothers how to prepare and administer oral rehydration therapy. The Mass Media and Health Practices Project (see Stanford University and Applied Communication Technology 1985) used a lottery as a device to encourage women to learn the procedure, which was explained through radio broadcasts and a pictorial flier. In the lottery, villages were randomly selected each week to be the site of a health fair. At the fair, women who demonstrated knowledge of oral rehydration therapy were rewarded with a small prize (such as a bar of soap) and a chance at winning a large prize.

Information incentives have fewer apparent disadvantages than others we discuss. They need not be tied to use of any particular method of contraception, nor even to use of contraception at all. Thus, they entail no monitoring costs. The payments need not be large. A program of information incentives can be limited to a short time in a particular community. We know of only one example of information incentives specifically for family planning (see section IV below).

High costs of early adoption of contraception. Poor information about contraception raises the costs of early adoption for particular individuals or couples. For the same reason, early adopters of contraception lower the costs of subse- 
quent adoption for others by providing reliable and specific information about the risks and benefits of contraception. Because early adopters do not take into account the benefits they provide to others, the adoption rate is slower than would be socially optimal.

As has been and is the case with agricultural innovations, as long as there is some unevaluated chance of a disastrous outcome, individuals may be justifiably skeptical of official assurances of low risk and high reward. They may put much more credence in the experience of their neighbors. To the extent that family planning is regarded as particularly risky, the demonstration effect-once pioneers verify the innovation's efficacy and safety-could be particularly important.

Similar dynamics might prevail where social pressure or conformity weigh heavily on the individual's freedom of choice. In many societies, social norms strongly shape the costs and benefits of individual behavior. It is easy to imagine a situation in which each family would find fertility limitation advantageous, were it not for the fear of violating social norms and incurring social sanctions (Crook 1978). In such a situation, coordinated action could change norms. Although initial innovators would encounter social resistance, we would expect a "tipping" effect (see Schelling 1978). Once a critical percentage of families had adopted family planning, the old social norm would be undercut, and the other families would follow suit. ${ }^{6}$

Early adopter incentives, like information incentives, have certain advantages, particularly if limited to reversible methods of contraception. Incentives for early adoption could be offered only to groups or in communities where contraceptive prevalence is nearly zero, and only to a predetermined proportion of a particular group or target community (for example, the first 10 percent to apply). As with information incentives, verification of actual contraceptive use is not, strictly speaking, necessary; it is the appearance or public acknowledgment of use that is critical. ${ }^{7}$ Finally, the incentive need not be monetary; where social pressure is a factor, a prestige-related award might be more appropriate. ${ }^{8}$

6. Some evidence for the importance of demonstration or social-pressure effects is provided by the Taichung experiment (Freedman and Takeshita 1969). Neighborhoods in Taichung were randomly assigned to experimental or control groups. Family planning fieldworkers visited households in the experimental group. Freedman and Takeshita found that, holding neighborhood status (experimental vs. control) constant, adoption rates were higher when adjacent neighborhoods were in the experimental group. It might be hypothesized that within-neighborhood demonstration effects are stronger.

7. To discourage purely opportunistic claimants, the award could be given in two installments: the first given immediately, the second after two years, contingent on no births in the interim. The restricted number of awards would facilitate the more complicated record-keeping and verification needed for a deferred award.

8. Incentive schemes in which the community as a whole receives payments linked to contraceptive prevalence can be interpreted as an attempt to reverse the polarity of social pressures for high fertility. For example, a community-based experiment in Thailand (Weeden and others 1986) linked grants to a village loan fund with the village's contraceptive prevalence level. Although the study reported that experimental villages experienced a greater rise in contraceptive prevalence and a greater decline in "unmet need," the 
Failure of credit and insurance markets. In many countries, significant proportions of women say that they would like to limit their fertility yet do not do so. This condition of "unmet need" for fertility limitation is met by one-quarter of married fecund women in Bangladesh, one-fifth in Nepal, and one-eighth in Egypt (see Boulier 1985). ${ }^{9}$ An additional, and large, proportion of women report unmet need for birth spacing.

If the benefits to the couple of a smaller family-reduced expenditure on food, more time to devote to work or leisure, increased maternal attention per child, reduced health risks-substantially outweigh the costs of adoption of contraception (and the pleasures associated with a larger but poorer family), why doesn't the couple itself finance the adoption costs? There are two possible reasons. First, many poor couples, lacking collateral, are not creditworthy. Second, couples may be able to finance the average cost of adopting contraceptives but could not afford-and, in the absence of insurance markets, cannot insure againstthe small possibility of complications entailing a long period of unemployment. In these conditions of credit or insurance market failure, subsidizing adoption costs might boost acceptors' welfare by far more than the subsidy.

How large, in practice, are acceptance costs? They obviously vary widely, depending on the distance of potential clients to the nearest service point and depending on the type of contraception. Sterilization and insertion of an intrauterine device (IUD) are the only ones likely to impose substantial costs in lost work; the pill could (rarely) involve medical complications.

A 1984 study of acceptors of sterilization in Bangladesh (see Cleland and Mauldin 1987) indicated that for tubectomy and vasectomy acceptors, out-ofpocket transportation and food costs averaged almost twice the average daily wage for male workers. Sixteen percent of acceptors spent more than three times the average daily male wage. More than one-third of acceptors eventually faced additional medical complications, and 11 percent eventually spent a total of almost ten times the average daily male wage. Recuperation time averaged four days for men and ten for women, but was also subject to considerable variation. Some 8 percent of men and 37 percent of women needed more than fifteen days to recuperate. Thus, although mean acceptance costs are relatively low, there is a substantial risk of relatively high costs.

Are these costs beyond the ability of acceptors to finance? In the survey of Bangladesh tubectomy acceptors, 42 percent said that they would have been unable to undergo the operation in the absence of the payment offered (of almost six times the average daily male wage; Cleland and Mauldin 1987). The sample was not representative, however, and it is possible that responses were

authors conclude that the incentive scheme did not succeed because it directly galvanized community pressure. Instead, the increase in contraceptive prevalence was linked to enthusiastic promotional activity by the loan committee members, who were motivated by intervillage rivalry and by the prospects of administering a large loan fund.

9. Demographers use the term unmet need to signify would-be demand for contraception were the price of contraception (including psychic as well as monetary costs) zero (see Boulier 1985). 
biased by a desire to please the interviewer. A stronger test is provided by looking at behavioral data and focusing on the adoption of nonpermanent contraceptives, where acceptance costs are relatively low. Evidence on the effect of distance to a health center (a proxy for acceptance costs) on contraception is provided by Entwisle and others 1984, based on a survey in rural Thailand. ${ }^{10}$ No effect of distance was found for the group aged 15-24 years old (the least likely to be using contraception), but proximity to a health center significantly boosted the odds of using contraception for both the age 25-34 and 35-44 groups. For the former, the odds of using contraception were 67 percent to 80 percent greater (for a modal woman, with low education, who desires no more children) when a health center was located within four kilometers of her residence. ${ }^{11}$ This evidence suggests that financing problems are a constraint, despite relatively low costs.

One-time payments for contraceptive adoption are often used for sterilization (Satia and Maru 1986; Thapa and others 1987), occasionally for the IUD, but infrequently for other methods. This may reflect a combination of more serious financing constraints for sterilization and the IUD, and practical difficulties in monitoring adoption of other methods. The size of the sterilization incentives has varied widely; it has been as high as one month's per capita income (in Sri Lanka in 1983). ${ }^{12}$

If financing problems are a constraint to adoption, a first and best policy response would be to supply the missing credit and insurance services. But if markets fail to provide these services, such services may also prove administratively difficult for government agencies to provide. The most common alternative is greatly improved access to family planning services, to lower financial costs to potential users. In some settings, an incentive for contraceptive adoption, with the size of the incentive tied, ideally, to method-specific and individual-specific adoption costs, could be less costly. The insurance function is more difficult to fulfill, although it might be possible to tie extra payments, after the fact, to medical complications.

10. In this study distances are measured objectively, rather than by respondents' estimates; and the health centers predate the family planning program, reducing the possibility of a biased relationship due to the targeting of clinics at areas with low demand for family planning. The study controls for respondents' education and stated desire for no more children, providing a strong test of whether distance matters by minimizing the possibility that distance from a health station is a proxy for traditional attitudes rather than difficult access.

11. Desire for no more children, an explanatory variable, is actually endogenous; thus, the pure effects of distance are probably understated. Distant women are more likely to be traditional, so a distant woman who nonetheless reports wanting no more children is probably more motivated to use contraception than her less-isolated counterpart. Hence, the fall-off of contraceptive use with distance may appear more gradual than it actually is.

12. In India (Satia and Maru 1986), payment levels designated as compensation for lost wages rose from Rs10 in 1964 to Rs100 (US\$9.00) in 1983-the latter approximately equivalent to ten to twelve days' wages. An additional Rs40 (men) or Rs70 (women) is designated as compensation for drugs, food, and transport, and many states offer supplementary amounts. In 1983, Sri Lanka offered Rs500 (US\$27.50), approximately equivalent to one month's per capita income. 
Against the advantage of overcoming financing problems, these incentives have two major disadvantages. First, they may be difficult to target; that is, many of the claimants may not in fact face financing difficulties. Second, these payments may loom very large for the poorest, and may constitute entrapment. The problem of entrapment is greatest for sterilization, because the procedure is irreversible and because the net financial benefits of acceptance could be relatively large for individuals with low acceptance costs (these issues are discussed at greater length in section III).

Procrastination or myopia. A frequently cited ethical problem associated with incentives is that the prospect of short-term gains may tempt myopic individuals to act contrary to their long-term interests. The converse problem, rarely mentioned, may be more pervasive: myopic individuals may be deterred by short-term costs from actions that would yield them long-term benefits (in other words, it is their inaction rather than their action that induces regret).

This latter category does not fall into any usual classification of market failure by economists. In effect, it represents a challenge to the conventional notion that actual behavior reflects underlying preferences (that is, that there is a welldefined utility function). Schelling (1984) and Loewenstein and Thaler (1989) discuss a related class of problems, which they find both pervasive and difficult to reconcile with received economic theory. In a number of circumstances, people act as if they had two selves with conflicting time preferences: one "self" focused on the moment, the other concerned with the long term. Some common examples include dieting; abstention from alcohol or tobacco; saving; and procrastination in general. Schelling points out that a great many people will voluntarily arrange to put themselves in situations that compel them to behave in accord with the long-term set of interest. For example, people join forced-saving Christmas clubs, even though voluntary savings yield higher interest rates; they pay to be subjected to an enforced diet; they give their car keys to friends before drinking, with instructions to ignore drunken pleas for the keys' return.

Along these lines, we may hypothesize that the immediate psychic costs of adopting contraception are for some people large enough to induce severe procrastination, despite long-term benefits of a smaller family or more evenly spaced births. This would particularly be the case if there is uncertainty about health effects, fear of relatives' criticism, or concerns about the attitudes of health personnel toward poor or uneducated persons (see Bogue 1983, who cites the first two of these anxieties as major psychic costs deterring contraceptive use).

Is procrastination a cause for public policy intervention? Many policy analysts would be reluctant to interfere with an individual's preferences. But this reluctance is founded on the assumption of consumer sovereignty that is questioned here. If a case can be made that procrastination in contraceptive adoption leads to a long-run reduction in the procrastinator's welfare, then intervention may be justified. (There is a rough analogy with seat belt laws, which claim to overrule 
individuals' short-term preferences to promote their long-term welfare.) A possible policy instrument would be an incentive for contraceptive adoption which counterbalances the psychic costs leading to procrastination, allowing the individual to place greater emphasis on the future consequences of the contraceptive decision.

There may be more direct ways of overcoming psychic costs leading to procrastination, however. If potential acceptors are deterred by dirty clinics or insensitive staff, it may make more sense to upgrade facilities and retrain providers than to offer acceptor incentives.

Alternatives to incentives. As table 1 shows, incentives are seldom the sole alternative to correction of the particular problems discussed above. In particular settings, the cost-effectiveness of incentives should be evaluated relative to that of increasing the number of family planning service points, greater use of fieldworkers, more emphasis on information and communication through the mass media or in the context of clinic services, introduction of community-based distribution systems using village workers, and so on.

\section{External Costs of Childbearing}

Incentives also may be a mechanism by which society as a whole assures that individual couples internalize more fully the costs to society of their decision to have an additional child. We review first the possible sources of externalities and then treat the set of policies, including incentives, that can be used to correct for any externalities.

Sources of externalities. The concern about population growth at the national or social level is often based, implicitly or explicitly, on the idea that there are negative externalities to childbearing: my decision to have a child imposes costs on society that I do not take account of (see Simon 1977 for a discussion of both positive and negative externalities to childbearing). Despite the popularity of this assumption, there has been relatively little theoretical work (but see Willis 1987; Nerlove, Razin, and Sadka 1987), and almost no empirical work (except Lee and Miller, this volume), describing the nature and magnitude of these externalities.

Lee (1988) describes a number of externalities to childbearing related to public goods or common property. First, when there is public national wealth (for example, state-owned lands or mineral deposits) the birth of a new citizen dilutes everyone else's claim on this jointly owned property. Similarly, if there are nonprivatizable, congestible common property resources such as fisheries and airsheds, an additional birth reduces per capita consumption of the resource. If the resource is not properly managed, as in the classic "tragedy of the commons" scenario, in which access to the resource is unlimited, then population growth exacerbates the losses due to mismanagement.

A formally similar situation occurs when citizens are entitled to public transfer payments (social security) or subsidized services (education, health), consume 
public goods, and are obligated to pay taxes. In such situations, the birth of an additional citizen adds both to public revenue and expenditure, resulting in positive and negative externalities to other taxpayers. Depending on the amounts and life-cycle timing of tax payments and receipt of benefits, net externalities could be positive or negative (Lee and Miller, this volume).

An important pecuniary externality to childbearing occurs in the labor market. As population, especially rural population, increases, the wages of labor go down, and rents increase. For individual landless or land-poor laborers it is rational to have many children as a strategy for maximizing old-age income. When all pursue this strategy, however, wages are depressed, and both the parents' living standards and those of their children are reduced below their expectations. Hence, one poor family's decision to have children imposes costs on its peers; if all join in a labor-supply cartel and agree to have fewer children, the group's income would increase.

As many authors ( $\mathrm{Ng} 1986$; Willis 1987; Lee and Miller, this volume) have pointed out, this is not a "true" externality, because it operates through the market. Although wages are depressed by population growth, rents are boosted; high fertility is potentially Pareto-superior to low fertility, assuming that landlords redistribute some of their rents.

In practice, however, the landlords are unlikely to redistribute their rents. From a policy viewpoint, the demonstration that there are no true externalities to childbearing may be of limited interest. Where income inequality and absolute poverty are great, and equity is a policy goal, a labor-supply cartel may be one of the most feasible means of redistributing wealth. It therefore makes sense to think of externalities to childbearing as operating within the group of laborers. ${ }^{13}$

A final source of childbearing externalities occurs when couples care about their relative-rather than absolute-family size. A family's voice in the village council, prestige, physical security, or claim to the use of common property may depend on its size relative to the group (Crook 1978). When a couple has more children, they slightly increase the average family size in their group, making others relatively worse off. An attempt by each couple to have more children than the average family size is mutually frustrating: average family size increases, and no couple achieves the sought-after advantage, although all now have larger families to support.

Policy instruments: taxes. If childbearing imposes external costs, the standard economic remedy would be to impose a tax on children equivalent to the external costs. Then, assuming that couples have perfect control over their

13. Evenson (1988) provides estimates of the effect of population on wages and rents in North India. He estimates that a 10 percent decline in population would boost overall per capita income by 8 percent, boost per capita income of rural landless households by 15 percent, and reduce land rents by 25 percent, ignoring scale economies and induced investments associated with population density. If scale economies are taken into account, a reduction in population actually boosts land rents. 
fertility, a child would be born only if its value to its parents exceeded its total cost to society. The response to the tax depends on a couple's income; their taste for children (especially high-order children) relative to goods; and whether their children are net assets. If we make the standard assumption of diminishing marginal utility-so that the fifth child, for example, yields somewhat less satisfaction to its parents than the first-we would expect the tax to reduce family size, but probably not to zero. We would also expect the tax to have a larger impact on the fertility of poorer couples.

The welfare-economic approach to population policy implicit in this argument is very different from the standard outlook. Population policies commonly set a quantitative target for a reduction in the birth rate; how that reduction is allocated among families is treated as a secondary consideration, subordinated to logistical and managerial constraints in meeting the quantity goal. In contrast, the welfare-economic approach is principally concerned with the distribution of births, seeking to ensure that each birth is highly valued both by parents and by society. The sheer number of averted births is irrelevant. (Indeed, if there were external benefits to childbearing, fertility would be subsidized.)

These points are illustrated in figures 1 and 2 . Figure 1 shows the demand, $D$, for children $(n)$ of two different types of families. For simplicity, we assume that the price of children $C$ is the same for all family types. The effect of a child $\operatorname{tax} T$ depends on the elasticity of demand at the current price. Panel A shows a wealthy family, whose fertility is relatively insensitive to price. A tax equivalent to the external social cost of children reduces the family's demand from $n$ to $n^{*}$. In the absence of the tax, there is a social welfare loss, depicted by the shaded area. Panel B shows a poor rural family, with elastic demand for higher-parity children, but a very inelastic demand for the first two or three children. Figure 2 aggregates these private demands into an aggregate demand curve $D$. The private cost curve $C$ shows the private costs per child, assumed constant for simplicity. The social cost curve $C^{\prime}$ includes both private and external costs. The number of children born in a laissez-faire regime would be $N$, but the optimal number of children is given by $N^{*}$, and would be achieved through the imposition of a $\operatorname{tax} T$ equal to the difference between $C^{\prime}$ and $C$ at that point. The shaded triangle depicts the total welfare loss: these potential children impose costs on society greater than the enjoyment they bring to their parents. (We sidestep here the philosophical issue of how much weight to attach to the contingent future welfare of potential but as-yet-unconceived people; see Dasgupta 1987.)

Clearly the magnitude of this welfare loss depends not only on the size of the externality but also on the elasticity of demand. The incidence and effect of the tax depend on individuals' demand elasticities. Family B reduces fertility much more than family $A$ in response to the tax, but still has more children and pays a higher tax.

Such taxes have been used or proposed in several countries. China introduced explicit taxes on unauthorized second or third children in 1979 (Banister 1987). Provisions differed between provinces; in Sichuan, as an example, the penalty 
Figure 1. Demand for Cbildren by Individual Families
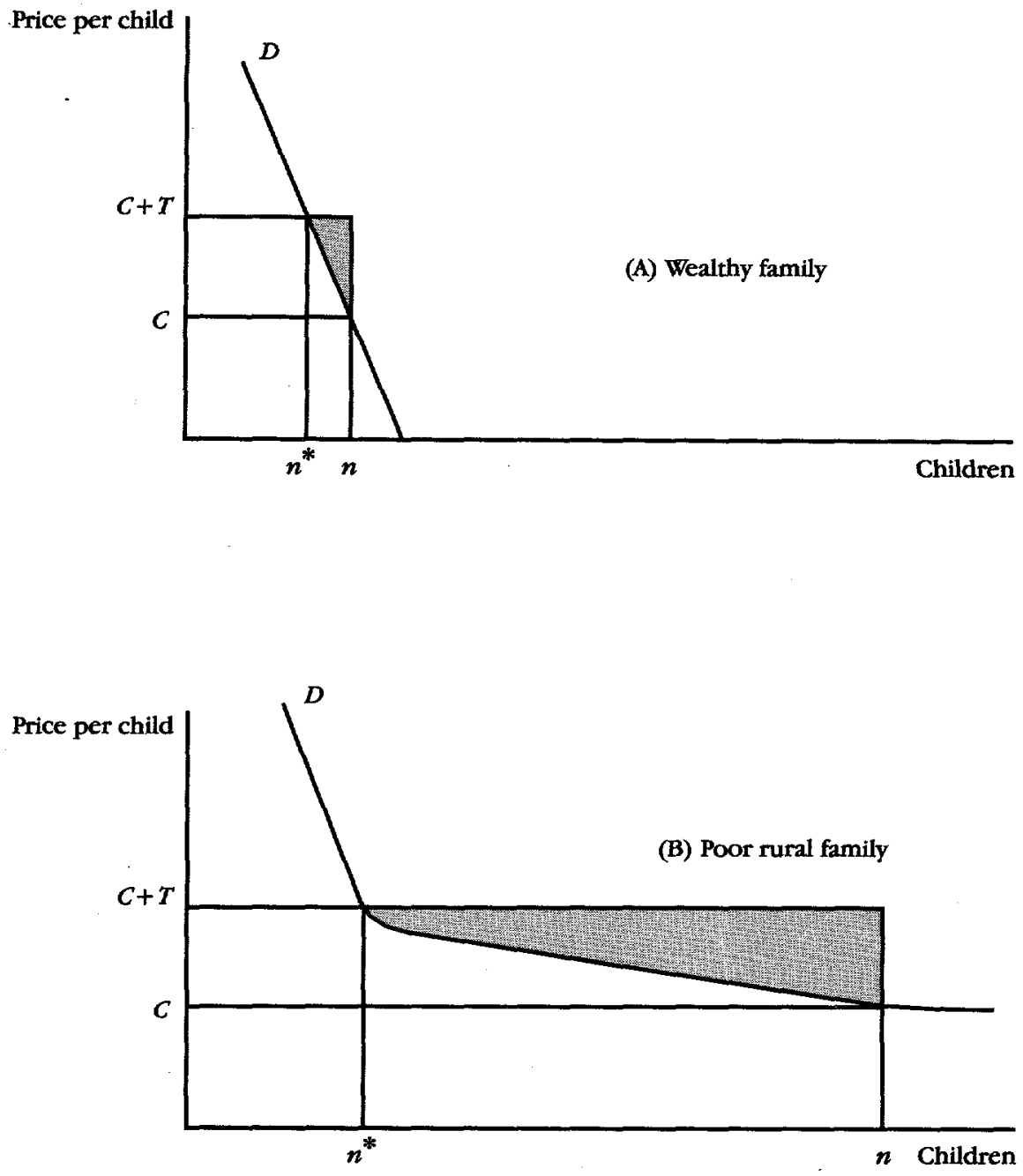
Figure 2. Social Costs and Benefits of Cbildren: Aggregate Demand for and Supply of Cbildren

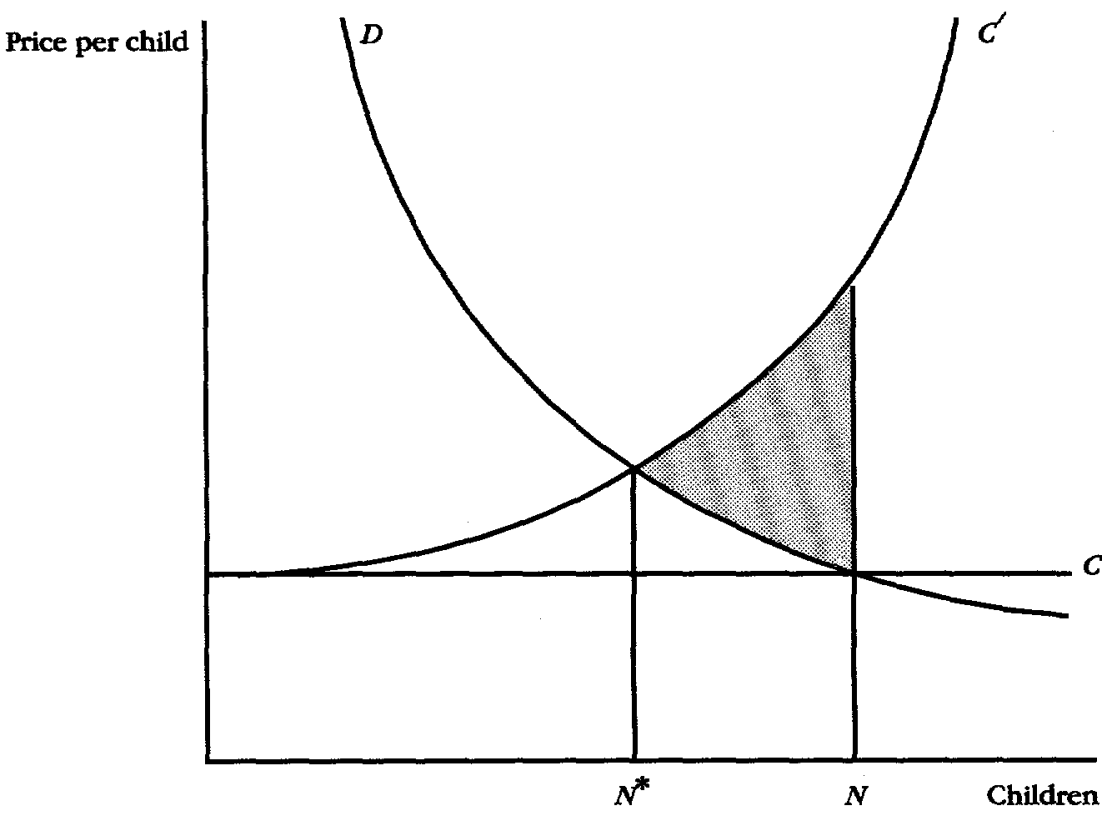

was a 10 to 20 percent income tax for seven years (Hardee-Cleaveland and Banister 1988). However, the effects of this economic penalty are difficult to disentangle from the intense political and social pressures that are applied to couples. Singapore, during the 1970 s, applied much more modest disincentives, whose effect may have been mostly symbolic (Chen and Fawcett 1979; Saw 1980). In any case the far-reaching economic and social changes in Singapore during this period make it difficult to isolate the effect of these disincentives.

Despite their theoretical advantages, child taxes are likely to hurt the poor. For the poor much more than for the rich, children are likely to be an important source of old-age income and security. Yet in no society-developed or developing-is it easy to borrow against the future earnings of one's children. Because of this failure of capital markets, it is easy to imagine a tax forcing a peasant to forgo the birth of a child whose financial security value alone is much greater than the tax. Even if capital markets posed no problem, an administratively simple tax would probably be highly regressive, and it might be difficult 
to guarantee that the tax revenues would be progressively distributed. ${ }^{14}$ There is a particular danger that the tax will penalize the children born, by accident or design, into large poor families.

Policy instruments: incentives. Rather than charging a family for the costs inflicted by its child on others, society might choose to bribe the family not to have a child, making the following sort of offer: "We, as a group, will save $\$ C$ for each child you choose not to have. We propose to share this dividend with you, as follows. When you are fifty, if you have no children, we will pay you $\$ 6 C$; if you have one child, we will pay you $\$ 5 C$, and so on." Once again, assuming perfect control of fertility, the only children born will be those whose social benefit is at least as great as their social cost. Assuming that the incentives are financed via progressive taxation, this version should be more favorable to the poor.

This scheme is equivalent to a lump-sum transfer combined with a child tax. Diagrammatically, its impact is similar to that depicted in figures 1 and 2, except that the demand curves simultaneously shift upward as a result of the transfer component.

Incentives for small families have been tried on a small scale in Taiwan (Finnigan and Sun 1972; Wang and Chen 1973) and in the No-birth Bonus scheme in South India (Ridker 1980). The latter program was instituted in 1971 at three tea estates with large female work forces. For each month during which a woman was not pregnant, the estate would pay 5 rupees (then about a day's wage) into a savings account. The savings account was redeemable, with 5 percent compound interest, at the end of the woman's childbearing years. However, 50 to 100 rupees were to be forfeited if the woman had a third child, 250 in the event of a fourth child, and the entire account in the event of a fifth child. Unfortunately, the experiment was marred by poor administration. Within a few years, the estates ceased to distribute and update the savings passbooks that constituted the participants' principal positive reinforcement for participation. As a result, by 1975 , only 8 percent of participating women were able to name any of the forfeiture conditions.

The collapse of the No-birth Bonus scheme highlights a serious disadvantage of this type of incentive program-its reliance on a competent and enduring administrative structure. To succeed, such an institution has to monitor a large number of people over a very long period of time, and to convince participants that an inflation-protected payment will be made dependably decades in the future. (There may be a paradox here. If high fertility is a strategy for coping with a politically disorganized society [Cain 1983; Organski and others 1984], then nations that are capable of inspiring the requisite confidence in small-family

14. Ideally, the tax would be child-specific; that is, it would compensate society for the external costs of that child. This might imply higher taxes for children born into poor households, if those children receive from society relatively more benefirs (schooling, health, and so on) net of taxes. 
bonds may not need them). In addition, the fiscal outlay may be very large, a point we discuss in section III.

It is sometimes proposed to use entitlements rather than money as a deferred incentive. For example, several Indian states give sterilization acceptors and their families preferred access to health services, education, and loans (Satia and Maru 1986). Where these services are not expanded to meet the extra demand, however, this becomes a disincentive. Such schemes have therefore been criticized because they can potentially penalize a child for the parents' action (Edgar and Greenawalt 1977).

Policy instruments: quotas. Quotas on childbearing are an alternative to taxes or incentives, but quotas are both less efficient and less equitable. They are inefficient because they do not balance social costs and social benefits in the manner shown in figure 2. That is, they permit children to be born to some parents who value those children only slightly, while denying, say, third and fourth children to others who value them greatly.

Quotas are superficially equitable if the same quota applies to everyone. However, quotas deprive the poor of an important resource without compensation (except the benefits of slower population growth, which may accrue to their permitted children, not to them); the rich are much less economically reliant on their children. A law forbidding both rich and poor to have a third child is no more equitable than the proverbial law forbidding both rich and poor to sleep under bridges.

\section{A Simple Benefit-Cost Framework}

Section II dealt with the potential welfare benefits that could result from incentives appropriately designed to counteract specific failures of markets and of individual decisionmaking. Potential welfare gains for families include reductions in the financial, emotional, and health burdens of unwanted births; alleviation of poverty; and increased shares of ownership of common property. We also alluded to the demographic impact-the number of births averted or deferred. However, it should be clear from our discussion that we believe that welfare benefits should be policymakers' ultimate concern. Demographic impact is only a crude proxy for those benefits, with the advantage of being more easily estimated. Moreover, it is possible to have welfare gains even in the absence of major demographic effects. For example, increased provision of sterilization to women past their prime childbearing years may relieve anxieties about health hazards or social stigmatization associated with late pregnancies.

Against the potential benefits of incentives, we can distinguish three kinds of costs. The fiscal cost comprises all public expenditures on the operation of the incentive program, including the incentives themselves. But the economic costs are simply the costs of administering the program, because the incentives are transfer payments that consume no resources.

Welfare losses are the third cost. As noted earlier, individuals may suffer welfare losses from incentives if the tax to finance the incentives falls heavily on 
them. But the potential welfare loss of most serious concern is that incentives will entrap individuals into actions against their long-term interest.

\section{Monitoring, Fraud, and Administrative Costs}

An incentive program has two difficult responsibilities. First, it must disburse or collect money, typically in large numbers of small transactions. Although this invites corruption, the success of the Bangladesh sterilization program in maintaining a strict audit system shows that the problem is solvable.

Second, the program administration must verify the incentive claimants' compliance with the incentive conditions. The cost of doing so (or the trade-off between verification and losses due to fraudulent claims) depends of course on the nature of the conditions. Sterilization incentives are popular, in part, because verification costs are relatively low; attempts at undergoing multiple sterilizations are easily detected. (Other conditions imposed by sterilization programs, including maximum age and consent of spouse, are not so easily verifiable, however.) Verification of the use of implantable contraceptives is also relatively easy. Providing incentives for IUD use, however, is a strategy that runs the risk of inducing women repeatedly to remove the IUDs. At the other extreme, verification of the use of pills or condoms is virtually impossible.

No-birth bonuses, discussed in section II, avoid method-specific bias by monitoring either nonpregnancy or birth but have formidable administrative requirements. A program that relies on birth monitoring presupposes a well-developed, evasion-proof vital registration system, one that is probably more sophisticated than most developing countries possess. A program that monitors nonpregnancy faces a trade-off between frequency of monitoring and losses due to noncompliance. In either case, positive identification and nationwide coordination are needed to reduce multiple claims by the same individual.

In sum, it is administratively difficult to devise incentives for long-term contraception that are not biased toward sterilization (or perhaps implantables). Payments to early adopters or incentives for information acquisition may be more feasible, however.

\section{Fiscal Costs and Targeting}

For many incentive schemes, the incentive payments themselves are likely to constitute the bulk of program expenditures. Because incentive payments are transfers and do not consume real resources, these payments are fiscal but not economic costs. Fiscal costs are important, however, because governments have a limited ability to raise revenues-which is to say that the people who pay the transfers care about their magnitude.

The fiscal costs of an incentive program are directly tied to the number of incentive claimants: people who meet the award criteria and receive incentive payments. But not all those who qualify for, and claim, the incentive actually change their behavior (for example, use contraceptives) as a result. As we noted in the preceding section, some claimants are frauds who do not actually meet the award criteria. Others are windfall claimants who would have met the award 
conditions even in the absence of the incentive. Still others do change their behavior but would have done so for more modest incentive payments. The rents collected by these latter two groups represent fiscal costs without social benefits.

Figure 3 illustrates the role of rents in incentive payouts, using a no-birth bonus scheme as an illustration. The two panels show the demand, $D$, for children of two types of couples. $C$ is the private cost of children; $C^{\prime}$ is the social cost of children. Offering a flat incentive payment of $I=C^{\prime}-C$ for each birth less than some maximum, $m$, results in payouts shown by the shaded rectangles; couple A receives a particularly large payment because their realized fertility, $n$, is low. (For expositional purposes, we make the unrealistic assumption that the demand curve does not shift upward as a result of the income-transfer component of the incentive.) Suppose, however, it were possible to pay each couple the minimum necessary to convince them to reduce their fertility to the socially optimal level, $n^{*}$. Couple $\mathrm{A}$ is nearly at that level, so only a small payment, $a b c$, would be necessary; couple $B$ requires a much larger payment, $a b c$, in panel $B$. The difference between the flat-rate incentive payments and the minimum necessary payments represents rents received under the flat-rate system.

Clearly the fiscal benefit-cost ratio of an incentive scheme can be increased by decreasing the amount of rents paid. This can be done by targeting incentive eligibility away from windfall claimants (such as couple A) and by customizing incentive levels to match individuals" "reservation prices" for behavioral change. For example, payments and eligibility might be related to age, sex, parity, and geographical region. However, it is easy to imagine situations in which targeting would be politically or socially unattractive: where, for example, fiscal efficiency dictates paying higher incentives to wealthier couples or concentrating incentives on a particular ethnic group.

\section{Entrapment, Myopia, and Welfare Costs}

Perhaps the greatest fear concerning client incentives is that they will tempt a myopic or ill-informed individual to sacrifice his or her long-term welfare for a short-term gain (we have examined the converse problem in section II). The problem arises mainly with regard to sterilization, because it is irreversible. Suppose that the poor have short time horizons or high discount rates, limited understanding of their options, and urgent needs. ${ }^{15}$ Then they will find a cash payment for sterilization irresistible, yet later they may regret their choice.

15. The possibility of limited understanding of their options by some clients is easiest to address. It is not difficult, in principle, to introduce screeners or counselors whose job is to ensure that sterilization adopters understand the risks and consequences of the operation. In practice, an independent survey of Bangladesh sterilization acceptors found that knowledge of sterilization's irreversibility, and of alternative, nonpermanent family planning methods, was virtually universal (Cleland and Mauldin 1987). In addition, 86 percent of male and 76 percent of female respondents had discussed the operation with someone who had been sterilized. However, Thapa and others (1987) reported that 14 percent of lowincome acceptors in a Sri Lankan sample did not know that vasectomies were irreversible. 
Figure 3. Rents and Incentive Payments in a No-Birtb Bonus Scheme

(a)

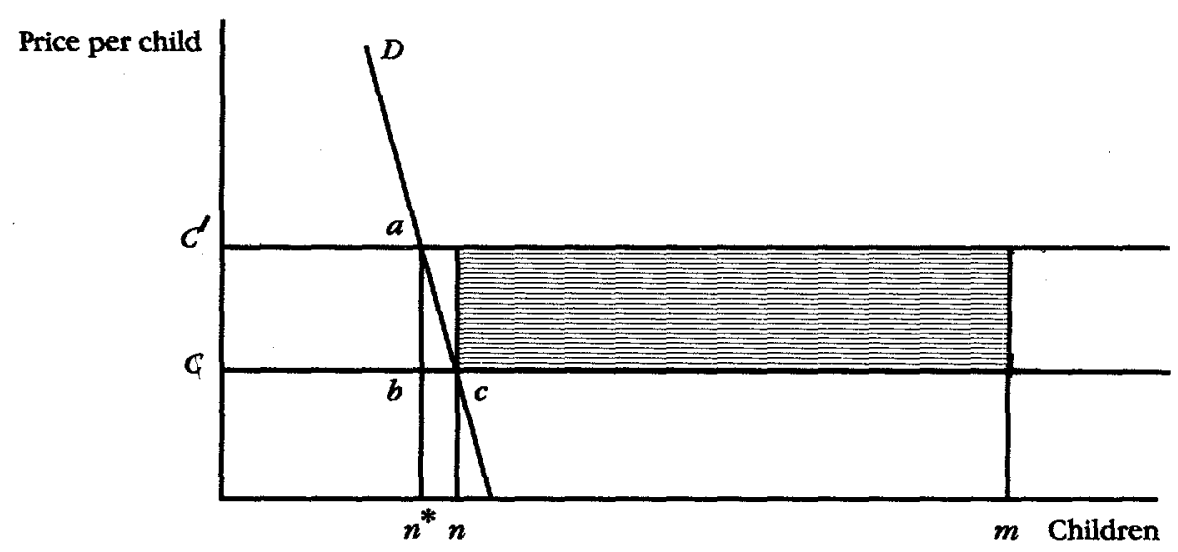

(b)

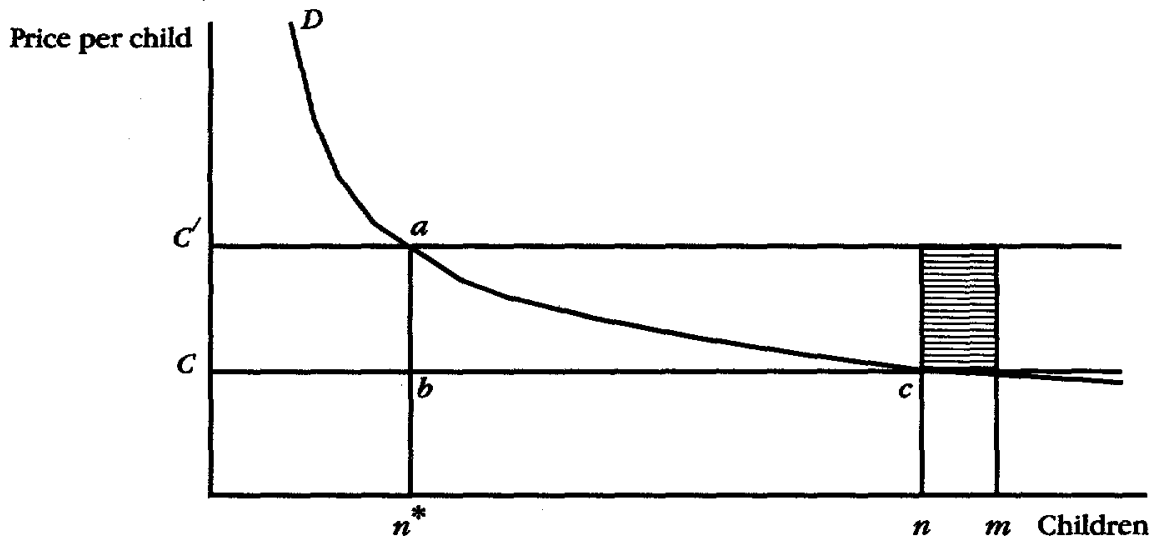


Myopic acceptors potentially could be screened out by using a deferred incentive (King 1974). For example, sterilization acceptors could be invited to return for a checkup a week or two after the operation, at which time the incentive would be paid. This has the added advantage of encouraging follow-up care. It has the disadvantage that it may undercut the value of the incentive as a device for helping people finance sterilization (see section II). This may not matter much if the incentive is more important as insurance against the cost of complications than as a means for financing average costs.

Empirically assessing myopia is difficult, but Cleland and Mauldin (1987) explore several possible avenues in assessing voluntariness among Bangladesh sterilization acceptors. The most direct approach is to ask acceptors if they regret their decision, or if they would like to reverse the operation, if that were possible. Although positivists may question the validity of the response to such questions (especially in a fatalistic culture), the results of the Bangladesh survey suggest that the responses were meaningful. The incidence of regret among tubectomy acceptors decreased with family size and increased if the woman had experienced the death of a child since her operation. A second, indirect approach is to evaluate the decision process. Among the Bangladesh acceptors, 98 percent of men and 93 percent of women said they had thought about the decision for more than a month; 98 percent of men and 82 percent of women said they had waited more than a day between making the decision and undergoing the operation. Again, a skeptic might question the meaningfulness of the responses.

A third approach is to examine the behavior of people suffering temporary income shortfalls. If their discount rates are very high, these people may be more likely to accept sterilization and to do so without deliberation. (Alternatively, one might argue that current privation prompts them to consider more carefully the long-term impact of a larger family size.) Cleland and Mauldin (1987) report that among vasectomy acceptors, those who reported inadequate food consumption during the two weeks before acceptance were more likely to have taken less than a month to decide to be sterilized. A behavioral extension of this approach might examine whether there are seasonal peaks in acceptance, for example, in the lean times just before harvest. Such an analysis would have to control carefully for seasonal labor market conditions, though, because the opportunity cost of recuperation also may be low in slack times before harvest.

\section{A Framework for Balancing Costs and Benefits}

Computing the costs and benefits associated with a particular incentive requires a variety of information. We need to know the structure of the incentive, which is defined by a set of rewards or penalties (for example, a cash payment); a set of behaviors or characteristics on which the rewards are conditioned (for example, adoption of a contraceptive); and a mechanism for mon- 
itoring compliance with the incentive conditions and administering the award or penalty. Then we need to answer three questions:

1. Who claims the incentive?

2. Who changes his or her behavior as a result of the incentive?

3 . What are the net welfare gains realized as a result of behavioral change?

In principle, given natural or experimental variation in the incentive structure, we could quantify the answers to the first two questions. That is, we could statistically estimate the probability that an individual claims the incentive, and changes his or her contraceptive behavior, as a function both of the incentive structure and the individual's characteristics. This would allow us to compute the fiscal cost (from the answer to question 1) and the effect on fertility, contraceptive prevalence, or contraceptive knowledge (question 2).

Translating contraceptive prevalence or fertility impacts into welfare impacts (question 3) is far more difficult. It involves quantifying the benefits of smaller families to individuals and to society, and assessing the hazards of entrapment and regret. We believe, though, that an attempt at putting even order-ofmagnitude bounds on these effects would be a useful exercise and would offer more guidance than do arbitrary population targets.

Ideally, the answers to these questions could be expressed as functions of the incentive structure. Even crude estimates of these functions would give some insight into the relation of costs and benefits to the magnitude of the incentive program. Consider, for example, the costs and benefits of the South Asian sterilization incentive programs. If financial barriers to adoption are relatively small, it is possible that most of the benefits associated with such incentives are exhausted at relatively low payment levels, whereas fiscal costs and possibly the incidence of regret might be expected to increase more than proportionately to payment levels.

Unfortunately, despite the controversy surrounding, and considerable expenditures on, the South Asian incentive schemes, we understand very little about the claim, behavior, or welfare functions involved (Cleland and Mauldin 1987 represents a heroic and impressive effort to answer these questions without variation in the incentive structure). There have been no experiments and little analysis of natural variation in the structure of these programs. It does appear that the claim rate is strongly related, at least in the short run, to the payment level. In Bangladesh, an October 1983 boost in the sterilization payment from about Taka 100 to Taka 175 was followed by a 143 percent increase in annual vasectomies. But the Sri Lankan family planning program serves as a neater natural experiment because of oscillations in the incentive offer (Thapa and others 1987). Between 1980 and 1983, the incentive payment jumped from 100 to 500 rupees, fell to 200 , and bounced back to 500 . The number of acceptances closely tracked the size of the incentive, with male acceptances exhibiting a greater incentive elasticity. The post-1983 male acceptance rate, however, was 
substantially below the 1980 peak response, suggesting that a significant fraction of the incentive-sensitive men accepted within a few months of the initial 500-rupee offer.

For sterilization, the behavior and claim functions are almost identical, differing only because of a minor amount of fraud. It is the welfare function that is crucial for policy analysis, and here we have even less information. We cannot even answer the demographic-impact question: do higher payment levels tend to attract older, less fertile acceptors? In principle, demographic impact should be quantifiable, but we do not have analyses linking payment levels to births averted. Still less is known about effects on health, per capita income, and measures of psychological well-being. Some interesting data from Bangladesh, however, suggest that the incidence of regret after sterilization is 2.5 times higher among women with two children than among women with three or more (Cleland and Mauldin 1987). Findings of this sort could be useful in designing the eligibility requirements for incentives.

\section{Are Incentives Immoral?}

Consider an incentive for small families or for contraceptive use with safeguards against the possibility of entrapment, so that acceptors understand the consequences of their actions and are not tempted by immediate payoffs. Is such an incentive immoral?

The question cannot be answered by economic theory. A philosophical treatment is beyond the scope of this paper, but see Bayles (1980) and Edgar and Greenawalt (1977) for comprehensive discussions. We confine ourselves to comments, from an economic viewpoint, on two aspects of the question.

First, are incentives coercive? Setting aside the case of myopia, consider a very poor but rational couple who opt after careful consideration for an incentive payment rather than a large family. Some argue that this constitutes coercion because the choice is so stark that the couple's decision is virtually predetermined. Yet it is for precisely this reason that an economic analysis claims that their welfare has been improved. It may be quite true that only poor people would opt for the incentive, but depriving them of the option would only make them worse off (see Schelling 1984). There is an important qualification, however: the incentive offer could be considered exploitative and immoral if the offer really should be an unconditional entitlement (Edgar and Greenawalt 1977). For example, we would consider it immoral for a government to offer disaster victims a small-family incentive while withholding emergency relief.

Second, many moral codes prohibit certain actions or transactions that might otherwise increase an individual's utility (for example, prostitution, or selling one's own kidney, or purchasing beer on Sunday). Economic analysis can point out losses in output or economic welfare from these restrictions, but it cannot claim that these losses outweigh maintaining the underlying value system.

For some cultures a bald choice between money and children may be unac- 
ceptable. Yet a culturally sensitive framing of the choice may serve to legitimize it; after all, implicit trade-offs between children and goods exist for most families. Thus, noncash incentives may be acceptable where cash incentives are not. In particular, incentives that support family norms-such as educational benefits-may be perceived as legitimate. (We note in passing that incentives that give educational priority to children in small families are equivalent to disincentives that penalize children born to large families, unless additional educational facilities are provided.)

Societies where fertility is believed to be too high are faced with what Calabresi and Bobbitt (1978) call a "tragic choice." This is a choice that must be made (in this case, a determination of whose fertility should be reduced) but whose framing violates cultural norms. As a result, the choices are made in a hidden or implicit manner. For example, many find it morally unacceptable to trade off the travel convenience of higher speed limits against the resultant increase in traffic fatalities; a cultural norm holds that life is infinitely valuable. However, the logical consequence of the norm-that automotive travel should be entirely prohibited-is also unacceptable. Setting a speed limit thus becomes a difficult exercise. Similarly, if the current level of fertility is deemed too high, then some scheme must be used to allocate the desired fertility reductions. As Calabresi and Bobbitt point out, societies use a variety of implicit economic and social mechanisms to allocate children among families, although generally avoiding recognition that these allocations embody value judgments about whose fertility should be reduced. Incentive schemes make this value judgment explicit and are therefore controversial.

\section{New Directions in Incentive Design and Analysis: The AmManpettai EXPERIMENT}

An ongoing program in Tamil Nadu, India, rewards clients in a manner that can be interpreted as providing an incentive to acquire information and to overcome procrastination. ${ }^{16}$ It is of particular interest here for two reasons. First, it avoids the risk of entrapment. Second, recently collected data make it possible to illustrate the applicability of the analytic methodology set out in section III.

\section{Background}

The Ammanpettai Family Welfare Program provided an incentive for trial adoption of pills, IUDS, and condoms in a rural area where knowledge of temporary methods of contraception was low (about 30 percent of the population) and

16. The program was designed by Janice and Carl Stevens and implemented through the Stella Maris Charity Foundation. The following account of the program's history draws on Stevens and Stevens $(1987,1988,1990)$. 
use negligible (about 3 percent). The motivating assumptions for program design were the following:

- That there is considerable latent demand for these methods by women who want to space births or who wish to stop childbearing but fear sterilization. (The government program has emphasized sterilization; in this area, female acceptors of sterilization greatly outnumber male acceptors.)

- That clinic-based education, combined with supervised trial use, is the most effective means of learning about the advantages and disadvantages of contraception.

A limited-term incentive was designed to induce these women to try temporary methods, on the theory that after the trial period, the now better-informed and satisfied users would continue to use contraception.

The project was designed as a controlled experiment. Beginning in 1987, women in a control group of villages were offered contraceptive supplies and information through fieldworkers and at a centrally located private clinic, where health services and a range of contraceptives were made available. Women in experimental villages (located the same distance from the clinic) were offered the same services and, in addition, an incentive to visit the clinic. Contingent on nonpregnancy, women were paid 20 rupees upon each of their first five clinic visits. (In the survey described below, the median reported monthly family income was 350 rupees; only 7 percent reported receiving less than 275 rupees.) Women could receive free supplies and services, but no payment, in subsequent visits.

Response to the incentive exceeded the capacity of the program, so experimental-village women were enrolled in two waves of 500, in May and November 1987. Although only fourteen control-village women applied to the program in the absence of incentives, subsequent recruitment by fieldworkers resulted in approximately equal numbers of reported contraceptive users in the two groups.

To evaluate the program's impact, the Gandhigram Rural Institute conducted baseline (March 1987) and follow-up (August 1989) random population-based surveys of married women, ages $18-45$, in both groups of villages. The following analysis employs data from the 1989 survey (Gandhigram Rural Institute 1989). This survey took place about fifteen months after the last of the five payments was made to participants in the second wave of enrollees in the experimental villages.

\section{Characteristics of Acceptors}

The incentive offer did not overcome traditional Muslim reluctance to visit clinics; among ninety-seven Muslim women in the sample, only one participated 
Table 2. Determinants of Incentive Program Participation

\begin{tabular}{|c|c|c|c|c|c|}
\hline Variable & Coefficient & $\begin{array}{c}\text { Standard } \\
\text { error of } \\
\text { coeffi- } \\
\text { cient }\end{array}$ & $\begin{array}{c}\text { Asymp- } \\
\text { totic } \\
\text { T-ratio }\end{array}$ & $\begin{array}{l}\text { Variable } \\
\text { mean }\end{array}$ & $\begin{array}{l}\text { Variable } \\
\text { standard } \\
\text { deviation }\end{array}$ \\
\hline Constant & -3.77598 & 5.18828 & -0.728 & 1.0000 & 0.00000 \\
\hline Wife's age & .001918 & 14447 & -0.006 & 27.556 & 4.6692 \\
\hline Wife's age squared/1,000 & .171542 & 5.53278 & 0.031 & 0.78095 & 0.26831 \\
\hline Ln monthly family income (Rs) & .397004 & 0.434148 & 0.914 & 5.8695 & 0.33851 \\
\hline Wife illiterate (D) & -.180891 & 0.253227 & -0.714 & 0.51111 & 0.50174 \\
\hline $\begin{array}{l}\text { Wife completed secondary } \\
\text { school (D) }\end{array}$ & -.739927 & 0.551785 & -1.341 & 0.08889 & 0.28564 \\
\hline $\begin{array}{l}\text { Husband completed secon } \\
\text { school (D) }\end{array}$ & -.364679 & 0.349083 & -1.045 & 0.18519 & 0.38989 \\
\hline Family owns no land (D) & .711211 & 0.391774 & 1.815 & 0.85185 & 0.35657 \\
\hline Christian (D) & .453755 & 0.294310 & 1.542 & 0.22222 & 0.41729 \\
\hline Scheduled caste & .484715 & 0.273713 & 1.771 & 0.25926 & 0.43986 \\
\hline Number of pre-1987 & & & & & \\
\hline $\begin{array}{l}\text { pregnancies } \\
\text { Number of pre-19 }\end{array}$ & .366090 & .229905 & 1.592 & 2.7852 & 1.821 \\
\hline pregnancies squared & -.043105 & .030190 & -1.428 & 11.052 & 16.508 \\
\hline
\end{tabular}

Note: Dependent variable; participation in incentive program (dummy) (sample restricted to experimental villages). Number of observations, 135 ; mean of dependent variable, 0.429630 . Probit estimates: $\log$-likelihood, -83.881 ; restricted (slopes $=0$ ) $\log -\mathrm{L},-92.233$; chi-squared (11), 16.704; significance level, 0.11693 . D indicates a dummy variable. Subsample: non-Muslim, nonsterilized, age under 38, at least one pre-1987 child, most recent birth after May 1983. Data available from authors.

in the incentive program. Table 2 presents a probit analysis of program participation among the remainder of the population. ${ }^{17}$

Several results stand out clearly: among non-Muslims, the program appeals to Christians; members of scheduled castes; the landless; and to women with more than three prior pregnancies. The program appears to have no differential attraction for the illiterate or the better-educated. Interestingly, the cash offer does not tend to attract those with low current incomes differentially; if anything, women from higher-income families have a slightly higher probability of responding, although the effect is not statistically significant.

In general, these results suggest that the program attracts those with plausible motives for wanting to control fertility (landless, high-parity women) rather than opportunists (the poor) or windfall claimants (the educated, who are more likely already to be familiar with temporary methods of contraception). It is successful in reaching one potentially disadvantaged or underserved group (the

17. In this and subsequent analyses, the sample was restricted to women who were less than thirtyeight years old, not sterilized, and with husbands who were not sterilized at the time of the survey, and who had at least one pregnancy at the time of the experiment's inception, but whose most recent birth had taken place after May 1983. These restrictions approximate the criteria for incentive eligibility, but they may introduce sample selection bias. Adjusting for personal and household characteristics, women in the experimental villages had slightly higher pre-experiment fertility and a lower post-experiment incidence of sterilization. 
scheduled castes), but it does not attract Muslims, who may also be underserved.

\section{Impact of the Experiment}

Actually, two experiments were carried out. First, in both the control and experimental villages, temporary contraceptives were actively promoted for the first time by fieldworkers. Although we lack full controls for this experiment, temporary-method prevalence in the control villages increased from 3.6 percent to 8.0 percent over the two-year period (Stevens and Stevens 1990). Heightened emphasis on temporary methods by the government family welfare program accounted for some of this increase, which shows the impact of a wider menu of contraceptive choice even in the absence of incentives.

In the experimental villages, however, the increase in temporary-method prevalence was far steeper, jumping from 3.2 percent to 18.3 percent of respondents, or nearly a quarter of nonsterilized respondents (Stevens and Stevens 1990). Virtually all of these women adopted pills or IUDs. To make sure that the differential in aggregate contraceptive prevalence is not caused by differences in the composition of the two groups of villages, we use microdata to adjust these results for personal and household characteristics. Although it is tempting to compare the program participants (incentive claimants) to nonparticipants, it

Table 3. Determinants of Current Temporary-Method Contraceptive Use

\begin{tabular}{|c|c|c|c|c|c|}
\hline Variable & Coefficient & $\begin{array}{c}\text { Standard } \\
\text { error of } \\
\text { coeffi- } \\
\text { cient }\end{array}$ & $\begin{array}{c}\text { Asymp- } \\
\text { totic } \\
\text { T-ratio }\end{array}$ & $\begin{array}{l}\text { Variable } \\
\text { mean }\end{array}$ & $\begin{array}{l}\text { Variable } \\
\text { standard } \\
\text { deviation }\end{array}$ \\
\hline Constant & -7.96947 & 4.02351 & -1.981 & 1.0000 & 0.00000 \\
\hline Wife's age & .225284 & .264183 & .853 & 27.613 & 4.5200 \\
\hline Wife's age squared $/ 1,000$ & -3.86923 & 4.65236 & -.832 & .78282 & .25844 \\
\hline Ln monthly family income (Rs) & .478646 & .274797 & 1.742 & 5.9168 & .41807 \\
\hline Wife illiterate (D) & -.318610 & .220263 & -1.446 & .50000 & .50109 \\
\hline $\begin{array}{l}\text { Wife completed secondary } \\
\text { school (D) }\end{array}$ & -.285042 & .397085 & -.718 & .10000 & .30065 \\
\hline $\begin{array}{l}\text { Husband completed secondary } \\
\text { school (D) }\end{array}$ & & & & & \\
\hline Family owns no land (D) & .261330 & .285460 & $\begin{array}{l}.703 \\
.915\end{array}$ & .81304 & .41003 \\
\hline Wife employed outside home & & & & & \\
\hline (D) & .176545 & .222473 & .794 & .39130 & .48911 \\
\hline Christian (D) & .173866 & .295124 & .589 & .13478 & .34224 \\
\hline Scheduled caste (D) & .638108 & .226185 & 2.821 & .27826 & .44912 \\
\hline $\begin{array}{l}\text { Number of pre-1987 } \\
\text { pregnancies }\end{array}$ & .421092 & .235620 & 1.787 & 2.6043 & 1.6441 \\
\hline Number of pre-1987 & & & & & \\
\hline pregnancies squared & -.053536 & .0348256 & -1.537 & 9.4739 & 13.712 \\
\hline Live in experimental villages (D) & .550549 & .209385 & 2.629 & .58696 & .49345 \\
\hline
\end{tabular}


then becomes difficult to disentangle the causal effects of the program from the determinants of the decision to participate. Of course, as always in nonrandomized social experiments, we have to admit the possibility that our adjustments are insufficient-that differences between the two groups are caused by some nonexperimental but unmeasured factors.

Table 3 presents a probit estimate for current contraceptive use, restricted to the non-Muslim population. Holding constant residence in a control or experimental village, use is much higher among two disparate groups: higher-income households, and the scheduled castes. Holding constant age, income, birth history, education, and religious and social background, residents of the experimental villages are much more likely to be using contraception. At the sample mean values of the independent variables, residence in the experimental villages is predicted to boost the likelihood of contraception from 0.16 to 0.32 ; the effect is significant at the 0.01 level.

Is this differential due to the incentive, or could it result from more active promotion by public or private fieldworkers in the experimental villages? Table 4 shows a breakdown of current users in the subsample by their initial source of information about the method. In gross terms, the excess of incentive-village users is accounted for by women who learned about the method at the clinic; all but one of these were recipients of the incentive.

\section{Implications}

Women opted to continue contraceptive use after incentive payments lapsed. So the program appears to yield net welfare improvements while avoiding the entrapment risks associated with irreversible procedures. The relatively low cost (both economic and fiscal) of the program, and its appeal to relatively young, low- to medium-parity women, suggests that the program is a cost-effective

Table 4. Number of Current Users of Temporary Contraception Methods by Initial Source of Information

\begin{tabular}{lcc}
\hline Source & Control villages & $\begin{array}{c}\text { Experimental } \\
\text { (incentive-offer) } \\
\text { villages }\end{array}$ \\
\hline Stella Maris Clinic (incentive source) & 6 & 29 \\
Government clinic & 1 & 3 \\
Government fieldworker & 5 & 3 \\
Relatives & 0 & 1 \\
Friends and neighbors & 3 & 5 \\
Radio and television & 3 & 2 \\
Past users & 0 & 1 \\
Ammanpettai Family Welfare Program & 0 & 1 \\
$\quad$ contact persons (fieldworkers) & 18 & 45 \\
Total users & & \\
\hline
\end{tabular}

Note: Subsample: non-Muslim, nonsterilized, age under 38, at least one pre-1987 child, most recent birth after May 1983, currently (August 1989) using modern temporary methods. Data available from authors. 
Table 5. Summary of Benefits, Disadvantages, and Alternatives to Incentive Schemes

\begin{tabular}{|c|c|c|c|}
\hline Objective (or benefit) & Incentive type & Disadvantages & Alternatives \\
\hline $\begin{array}{l}\text { Finance adoption } \\
\text { costs and insure } \\
\text { against complications } \\
\text { (principally for steril- } \\
\text { ization, where costs } \\
\text { are high) }\end{array}$ & $\begin{array}{l}\text { Immediate one-time } \\
\text { payment or deferred } \\
\text { one-time payment }\end{array}$ & $\begin{array}{l}\text { Possibility of entrap- } \\
\text { ment for one-time } \\
\text { payment; possibly a } \\
\text { large proportion of } \\
\text { windfall claimants }\end{array}$ & $\begin{array}{l}\text { More clinics (to } \\
\text { reduce travel costs) }\end{array}$ \\
\hline $\begin{array}{l}\text { Increase diffusion of } \\
\text { accurate information } \\
\text { about contraception; } \\
\text { overcome procras- } \\
\text { tination }\end{array}$ & $\begin{array}{l}\text { Payment for attend- } \\
\text { ing informational } \\
\text { presentations; } \\
\text { Ammanpettai-type } \\
\text { limited-period non- } \\
\text { pregnancy incentives }\end{array}$ & $\begin{array}{l}\text { Possibly a large pro- } \\
\text { portion of windfall } \\
\text { claimants }\end{array}$ & $\begin{array}{l}\text { More fieldworkers; } \\
\text { IEC }\end{array}$ \\
\hline $\begin{array}{l}\text { Overcome costs } \\
\text { (uncertainty, social } \\
\text { disapproval) for early } \\
\text { adopters in low con- } \\
\text { traceptive prevalence } \\
\text { areas }\end{array}$ & $\begin{array}{l}\text { One-time payments } \\
\text { or prestigious awards } \\
\text { for early adopters } \\
\text { only; Ammanpettai- } \\
\text { type scheme with lim- } \\
\text { ited enrollment }\end{array}$ & Untried & IEC to change norms \\
\hline $\begin{array}{l}\text { Equilibrate social } \\
\text { costs and benefits of } \\
\text { childbearing }\end{array}$ & $\begin{array}{l}\text { Child taxes or small- } \\
\text { family bonds }\end{array}$ & $\begin{array}{l}\text { Taxes: apt to be } \\
\text { regressive; small- } \\
\text { family bonds; require } \\
\text { sophisticated admin- } \\
\text { istrative apparatus }\end{array}$ & $\begin{array}{l}\text { Changes in socio- } \\
\text { economic environ- } \\
\text { ment favoring small } \\
\text { families }\end{array}$ \\
\hline
\end{tabular}

alternative to sterilization incentives and may also be able to substitute, to some extent, for fieldworkers. ${ }^{18}$ (It is likely that the choice is not one of fieldworkers versus incentives but rather of the proper mix.)

\section{Policy and Research Recommendations}

Table 5 summarizes the potential rationales or objectives for incentives; the associated incentive design; potential weaknesses of the incentives; and alternative means of achieving the objective. Our principal points are as follows:

- Incentive schemes are not all-purpose tools for population policy but are possible responses to particular problems or market failures. Policy analysis should start by identifying a problem and then choosing among available policy responses, including appropriately designed incentives.

- There is a basic distinction between incentives that remove barriers to contraceptive adoption and incentives that compensate for externalities to childbearing. The latter are more difficult to justify (just as externalities to childbearing are difficult to demonstrate); the appropriate amounts are not obvious; and

18. Stevens and Stevens (1988), in a preliminary analysis, concluded that the program was costeffective. They estimated an economic cost of Rs76 per program participant, compared to a very rough estimate of Rs650 per acceptor for the government program. The estimates in table 2, along with data on administrative costs, would now permit a more definitive analysis. 
because of monitoring costs they are difficult to implement in a way that is not biased toward sterilization. Among the former, incentives to encourage clients to acquire information have several advantages; in contexts where information about contraceptives is poor, this kind of incentive may be a cost-effective substitute for fieldworkers, without the danger of entrapment and at relatively modest administrative cost.

- To evaluate the costs relative to benefits of incentives and their costeffectiveness relative to other programs requires better information on who responds to incentives, and with what effect, particularly with regard to the large sterilization incentive programs of South Asia. Key issues are assessing the characteristics of acceptors who are prone to later regret; targeting incentives away from windfall claimants; and estimating the response rate as a function of incentive level and conditions. Ideally, one would like an experiment (designed or natural) in which incentive levels varied between districts; data on individual responses would be necessary to analyze the impact of incentives.

- The Ammanpettai program of incentives for information acquisition represents a potentially fruitful direction for incentive design. It has the advantages of information incentives noted above and appears to have been effective in increasing women's contraceptive options, use, and welfare.

\section{REFERENCES}

Banister, Judith. 1987. China's Changing Population. Stanford, Calif.: Stanford University Press.

Bayles, Michael D. 1980. Morality and Population Policy. Tuscaloosa: University of Alabama Press.

Becker, Gary, and H. Gregg Lewis. 1973. "On the Interaction Between the Quantity and Quality of Children." Journal of Political Economy 81 (no. 2, part 2): 279-88.

Behrman, Jere R. 1989. "The Simple Analytics of Contraceptive Social Marketing." World Development 17, no. 10: 1499-1521.

Birdsall, Nancy. 1989. "Economic Analyses of Rapid Population Growth." World Bank Research Observer 4, no. 1: 23-50.

Bogue, Donald J. 1983. "Normative and Psychic Costs of Contraception." In R. A. Bulatao and Ronald D. Lee, eds., Determinants of Fertility in Developing Countries. New York: Academic Press.

Boulier, Bryan L. 1985. Evaluating Unmet Need for Contraception: Estimates for Thirty-Six Developing Countries. World Bank Staff Working Paper 678. Washington, D. C.

Cain, Mead. 1983. "Fertility as an Adjustment to Risk." Population and Development Review 9, no. 4: 688-702.

Calabresi, Guido, and Philip Bobbitt. 1978. Tragic Choices. New York: Norton.

Chen, Peter S. J., and James T. Fawcett, eds. 1979. Public Policy and Population Change in Singapore. New York: Population Council.

Chomitz, Kenneth M. 1984. "A Relativistic Model of Labor Supply." Ph.D. dissertation, University of California, Irvine. 
Cleland, John, and W. Parker Mauldin. 1987. Study of Compensation Payments and Family Planning in Bangladesh. Dacca: National Institute of Population and Training.

Crook, Nigel R. 1978. "On Social Norms and Fertility Decline." In G. Hawthorn, ed., Population and Development. London: Frank Cass.

Dasgupta, Partha. 1987. "The Ethical Foundations of Population Policy." In D. Gale Johnson and Ronald D. Lee, eds., Population Growth and Economic Development: Issues and Evidence. Madison: University of Wisconsin Press.

Easterlin, Richard, and Eileen Crimmins. 1985. The Fertility Revolution: A SupplyDemand Analysis. Chicago: University of Chicago Press.

Edgar, Harold, and Kent Greenawalt. 1977. "The Legal Tradition." In Robert M. Veatch, ed., Population Policy and Ethics: The American Experience. New York: Irvington.

Entwisle, B., A. I. Hermalin, P. Hamnuasilpa, and A. Chamratrithirong. 1984. "A Multilevel Model of Family Planning Availability and Contraceptive Use in Rural Thailand." Demography 21, no. 4: 559-74.

Evenson, Robert E. 1988. "Population Growth, Infrastructure, and Real Incomes in North India." In Ronald D. Lee and others, eds., Population, Food, and Rural Development. New York: Oxford University Press.

Finnigan, Oliver D., and T. H. Sun. 1972. "Planning, Starting, and Operating an Educational Incentives Project." Studies in Family Planning 3, no. 1: 1-7.

Freedman, Ronald, and John Y. Takeshita. 1969. Family Planning in Taiwan: An Experiment in Social Change. Princeton, N. J.: Princeton University Press.

Gandhigram Rural Institute, Faculty of Development, Department of Applied Research. 1989. "Population Based Survey Research: A Follow-up Survey of the Introductory Cash Incentive Programme on Family Welfare and Child Spacing in Ammanpettai, Thanjavur." Gandhigram Rural Institute Research Study, Gandhigram, India. Processed.

Hardee-Cleaveland, Karen, and Judith Banister. 1988. "Fertility Policy in China, 198688." Population and Development Review 14, no. 2: 245-86.

King, Timothy. 1974. Population Policies and Economic Development. Baltimore, Md.: Johns Hopkins University Press.

Loewenstein, George, and Richard H. Thaler. 1989. "Anomalies: Intertemporal Choice." Journal of Economic Perspectives 3, no. 4: 181-93.

National Research Council. 1986. Population Growth and Economic Development: Policy Questions. Washington, D. C.: National Academy Press.

Nerlove, Marc, Assaf Razin, and Efraim Sadka. 1987. Household and Economy: Welfare Economics of Endogenous Fertility. New York: Academic Press.

National Research Council. 1986. Population Growth and Economic Development: Policy Questions. Washington, D. C.: National Academy Press.

Nerlove, Marc, Assaf Razin, and Efraim Sadka. 1987. Household and Economy: Welfare Economics of Endogenous Fertility. New York: Academic Press.

Ng, Yew-Kwang. 1986. "The Welfare Economics of Population Control." Population and Development Review 12, no. 2: 247-66.

Organski, M. F. K., Jacek Kugler, J. Timothy Johnson, and Youssef Cohen. 1984. Birth, Deaths and Taxes: The Demographic and Political Transitions. Chicago: University of Chicago Press. 
Rao, N. E., M. E. Khan, and C. V. S. Prasad. 1986. Health Sector Expenditure Differentials in India: A State and National Level Study. Baroda, India: Operational Research Group (sponsored by the Ministry of Health and Family Welfare).

Ridker, R. 1980. "The No-birth Bonus Scheme: The Use of Savings Accounts for Family Planning in South India." Population and Development Review 6, no. 1: 31-47.

Satia, J. K., and R. Maru. 1986. "Incentives and Disincentives in the Indian Family Planning Program." Studies in Family Planning 17, no. 3: 136-45.

Saw, Swee-Hock. 1980. Population Control for Zero Growth in Singapore. Singapore: Oxford University Press.

Schelling, Thomas C. 1978. Micromotives and Macrobebavior. New York: Norton.

-1984. Choice and Consequence. Cambridge, Mass.: Harvard University Press.

Simon, Julian L. 1977. The Economics of Population Growth. Princeton: Princeton University Press.

Stanford University and Applied Communication Technology. 1985. The Mass Media and Health Practices Evaluation in the Gambia: A Report of the Major Findings. Washington, D. C.: Academy for Educational Development.

Stevens, Janice, and Carl Stevens. 1987. "The Ammanpettai Introductory Family Welfare, Child-Spacing Program and Child Survival Program, Tamil Nadu, India: Progress Report." Bethesda, Md.: National Institute of Mental Health and Reed College. Processed.

- 1988. "The Ammanpettai Introductory Family Welfare, Child-Spacing Program and Child Survival Program, Tamil Nadu, India: Progress Report." Bethesda, Md.: National Institute of Mental Health and Reed College. Processed.

1990. "The Ammanpettai Introductory Family Welfare, Child-Spacing Program and Child Survival Program, Tamil Nadu, India: Progress Report." Bethesda, Md.: National Institute of Mental Health and Reed College. Processed.

Thapa, Shyam, Daya Abeywickrema, and Lynne R. Wilkens. 1987. "Effects of Compensatory Payment on Vasectomy Acceptance in Urban Sri Lanka: A Comparison of Two Economic Groups." Studies in Family Planning 18, no. 6: 352-60.

Wang, C. M., and S. Y. Chen. 1973. "Evaluation of the First Year of the Educational Savings Program in Taiwan." Studies in Family Planning 4, no. 7: 157-61.

Weeden, D., A. Bennett, D. Lauro, and M. Viravaidya. 1986. "An Incentives Program to Increase Contraceptive Prevalence in Rural Thailand." International Family Planning Perspectives 12, no. 1: 11-16.

Willis, Robert J. 1987. "Externalities and Population." In D. Gale Johnson and Ronald D. Lee, eds., Population Growth and Economic Development: Issues and Evidence. Madison: University of Wisconsin Press.

World Bank. 1984. World Development Report. New York: Oxford University Press. 



\title{
Comment on "Incentives for Small Families," By Chomitz and Birdsall
}

\author{
Paulina Makinwa-Adebusoye
}

Most governments of developing countries have seen their rapid rates of population growth-resulting from a sharp decline of mortality since World War II and from persistent high fertility rates-as creating a "population problem." Of course, population growth per se is not the villain; rather, it is unduly rapid population growth that retards governments' efforts to promote social and economic development.

Governments' efforts to address the population problem by influencing fertility levels usually consist of applying one or several of the following policy prescriptions:

- Information, education, and communication (IEC) campaigns;

- Propaganda to change pronatalist attitudes;

- Provision of family planning services;

- Manipulation of incentives and disincentives to effect desired fertility behavior;

- Pursuit of general or selective development to change the socioeconomic determinants of fertility such as education, infant and child mortality, and status of women;

- Coercion through state pressure and direct sanctions.

Intervention to influence fertility choices of individuals is based on demographic or socioeconomic considerations, health considerations, concern for human rights, and concern for justice and equity.

Many of the countries that perceive rapid population growth as a source of concern have favored benign family planning programs consisting of IEC campaigns, or the manipulation of public and private access to modern contraceptives on the one hand, and application of the Bucharest formula-"take care of economic development and population growth will take care of itself"-on the other. However, these have generally failed or are destined to fail to have the desired effect on fertility or to improve overall welfare. It therefore becomes important, as Chomitz and Birdsall's paper strongly implies, that countries con-

Paulina Makinwa-Adebusoye is professor of population geography and head of the Population Research Unit, Nigerian Institute of Social and Economic Research, Ibadan.

(C) 1991 The International Bank for Reconstruction and Development / THE WORLD BANK. 
cerned about the negative effects of rapid population growth on public welfare should engage in an intensive search for viable policies that would complement existing programs. Chomitz and Birdsall make a case for client-targeted family planning incentives as one such policy.

According to Chomitz and Birdsall, incentives for family planning are particularly useful, first, where markets for contraceptives or contraceptive information have failed and, second, where failure of individuals' decisionmaking has resulted in less-than-optimal childbearing that imposes externalities on society.

Where people have higher fertility than is optimal, the resulting rapid growth of population is seen as a major contributor to-if not the main cause ofcrowded cities, inadequate housing, shortage of infrastructural amenities, and continued illiteracy. Incentive schemes are also justifiable where unwanted births arising from contraceptive failures can jeopardize the health of mothers and children; impair human rights (that is, the basic right of individuals and couples to decide freely on the number and spacing of their children); and impinge on justice and equity.

The authors present a typology of incentives according to size and design to counteract each of several problems arising from the two specific market failures.

Incentives to correct failure of the market for contraceptive information and services and thereby to remove perceived barriers to contraceptive usage are more readily justifiable on the grounds that they represent payments to meet costs by various categories of acceptors: those who volunteer to receive contraceptive information; early adopters; and those who require compensation for costs of transport to service points, for salary loss, or for time lost in case of complications.

Incentives that compensate for failure of individuals' decisionmaking and resulting externalities are not so readily justifiable. Disincentives such as explicit taxes on unauthorized children, as tried in China, or the less stringent variety tried in Singapore in the 1970s, are discouraged on the grounds that such taxes are usually regressive and more likely to penalize the poor and children born into large, poor families. Incentives, a form of bribe to dissuade couples from having extra births, are preferred.

On the cost side of any incentive scheme are fiscal costs-all public expenditures including the incentive payment, economic costs of administering the program, and welfare losses incurred when myopic acceptors preferring immediate gains later regret their actions.

Chomitz and Birdsall underscore the administrative difficulties and economic costs of incentive schemes-particularly the opportunities for large-scale fraud engendered by small payments to millions of acceptors and the near impossibility of verification of claims. However, they consider these difficulties serious only in the case of incentives for long-term contraception and for methods other than sterilization or perhaps implantables.

The authors consider incentives in the form of payments for information 
acquisition and early adoption as feasible, and they cite the Ammanpettai program as an example of the successful application of such incentives.

To reduce the heavy fiscal costs involved in incentive schemes, the authors suggest eliminating payments that yield no welfare gains. One way of doing this is by avoiding windfall claimants-that is, those who meet the award conditions but would have small families even in the absence of the incentive. Another is by ensuring that incentive levels match individuals' "reservation prices" for behavioral change-that is, payment of the minimum necessary incentive, which may be less than the amount being offered.

The third cost, welfare losses incurred by myopic acceptors (especially acceptors of irreversible methods such as sterilization), is more difficult to prevent, because there is no satisfactory way of empirically recognizing and screening out myopic acceptors.

For making incentive choices with reasonable efficiency, the authors suggest a framework for prior analysis of alternatives by balancing costs and benefits. However, the knowledge requirements of the framework are quite formidable. Essential elements of the framework are an understanding of the structure of various incentives and the claim (who claims the incentives), behavior (who changes behavior as a result of the incentive), and welfare functions of incentives. To these should be added an understanding of the direct or indirect impact of population processes on the determinants of welfare. There is also the need to compare incentives with other fertility-influencing programs and alternative programs. In theory, knowledge of these relationships would facilitate a ranking of all possible programs, including the laissez-faire option and the selection of the best incentive policy package.

Lack of requisite data is mainly responsible for trial-and-error approaches in government policies. Incentive programs are particularly susceptible to pitfalls and inefficiencies because there is no well of past experience from which to draw. Little is known about claim, behavior, or welfare functions of various programs in the South Asian countries that have a long tradition of incentives.

Chomitz and Birdsall's paper raises important ethical, administrative, and political questions. On the ethical plane, one finds it easy to agree with the authors' views that incentives are neither coercive nor immoral. If one is to avoid paternalism, one must agree that individuals are best able to recognize their own interest. Therefore, they can be depended on to act on it and thus to ensure that they are as well off as can be after allowing for constraints that may curtail available alternatives. If this is so, incentives can be no more coercive than accepted cultural beliefs and practices (not government policies) that regard the unmarried or childless state (in a woman considered old enough) as deviant behavior. Although there is an ethical dilemma created in trying to decide between the right of individuals to exercise their freedom to choose the size of their families and governments' role as promoter of societal welfare, incentive schemes that permit individuals free choice between various options may avoid this dilemma. Furthermore, incentive or disincentive schemes should include 
safeguards for the protection of innocent third parties-usually children-who might be affected.

On the administrative level, the problems are less easily surmountable. A prominent impediment to the success of incentive schemes is their susceptibility to large-scale corruption and fraud. Even when incentives are for short periods and limited to those willing to acquire information and to early adopters of modern methods of contraception, avenues for corruption exist mainly because of the large numbers of people involved. For example, one Indian program involved more than ten cadres of officials ranging from teachers and public health workers to district superintendents of police. It is impossible to see how incentives on a large scale may not degenerate into a mindless and corruptionladen racket.

Still on the administrative level, the ability of governments in developing countries-particularly in Sub-Saharan Africa-to meet the cost of incentives is in doubt, especially under present conditions of austerity. As the authors of the paper have suggested, costs can be reduced in theory if windfall claimants are screened out and if incentives are not larger than individuals' "reservation prices." But no objective method exists of a priori identification of those two categories of potential clients.

Costs for incentive schemes in Sub-Saharan Africa may be much higher than in South Asia. The high wage structure and culture of high reward expectations in present-day Nigeria, for example, may necessitate higher levels of incentive payments to motivate behavioral change. Furthermore, governments that contemplate or have effected drastic cuts in their subventions for vital sectors whose welfare gains the public readily recognizes (such as health and education) may meet opposition to any move to reallocate incentive payments to undertakings the public views as of uncertain or only longer-term benefit (such as lower fertility).

Other administrative problems will arise from the level of confidence in governments' ability to fulfill promises. If Nigeria is any example, governments of Sub-Saharan African countries do not have a good record of redeeming promises. And the question of credibility is a complex one with many determinants. For example, the success of any incentive scheme will also depend on how well the problem of inflation is tackled.

As it becomes evident that existing programs are not enough to achieve desirable targets of fertility reduction, Sub-Saharan African countries may be expected in the near future to emulate the example of South Asian countriesnotably China, India, and Indonesia - and adopt "hard" population programs in the form of incentives and disincentives. A feasible African model of such a policy is indicated by current practices in Ghana and Tanzania, where there are limitations on tax deductions for children, and on paid maternity leave beyond a certain number of children or based on certain minimal birth intervals. Perhaps the attraction of these disincentives lies in their general acceptability, their nearcostlessness, and the lessened chance for corruption. Although limited to urban 
wage earners, these disincentives, if vigorously applied, may reinforce tendencies toward smaller family size.

Before looking "beyond family planning," however, there is a need to take stock of all available options and invigorate existing programs. A lot of fertility reduction can be achieved in Sub-Saharan African countries by a combination of activities on two fronts. First, the existing cultural roots of African high fertility can be undermined by lifting all or most of the existing pressures on women to bear children. The Nigerian population policy (Nigeria 1988) speaks to this strategy in its sections on the role and status of man in family life and on the role and status of women in development.

Second, vigorous pursuit of existing explicit population programs is necessary. In this regard, governments' commitments need to be better demonstrated than at present. Strong and up-front political commitment to existing family planning programs is still absent in many Sub-Saharan African countries. Some countries continue to devote very little budgetary allowance to fertilityinfluencing programs. Similarly, public commitment or the support of public opinion for the stated policy goal-fertility reduction-is nowhere assured. Under present parlous conditions in most countries, intensification of popular motivational campaigns, coupled with governments' vigorous pursuit of the demographic ends of existing programs, may result in faster declines in fertility levels than presently imagined.

\section{REFERENCE}

Nigeria, Federal Republic of. 1988. National Policy on Population for Development, Unity, Progress, and Self-reliance. Lagos: Federal Republic of Nigeria. 



\section{Floor Discussion of the Lee and Chomitz-Birdsall Papers}

On incentives for contraception, a participant noted that in his own study of an Indian program similar to the Ammanpettai program reported in the Chomitz and Birdsall paper, the medical officers all reported that incentives were necessary-without them the officers could not fulfill their quotas for sterilization. The women who had been sterilized also agreed that incentives were important, but for a different reason-the incentive payments were necessary to cover post-sterilization medical costs. The dangers of coercion and irreversibility were the greatest for the poor and for landless agricultural laborers, particularly during natural disasters. The participant reported that evidence from Indian studies showed that during famines or economic crises that had caused severe agricultural unemployment, all members of a scheduled caste in some villages had accepted sterilization in return for an incentive payment.

Prompted by a remark made by John Caldwell in the morning's conference session, another participant observed that one potential externality not discussed in Lee's paper related to joint family systems. In such arrangements, there is a good probability that one's own child will be brought up largely by somebody else; this externality would imply that parents would have more children, because they are diffusing the responsibility to support them but have the expectation of getting support from them later on. Against this is the probability that in a joint family, aged parents might receive support from other than their own children; this would argue for smaller families. If there was a bias-that is, if the probability of being supported in old age by one's own children is higher than the extent to which one has to support the children when they are young-there would be a tendency for larger families.

With reference to Lee's paper, a participant noted that concerns about income distribution and poverty were precisely the motivating factors for population interventions, and to relegate them, as the paper did, as special cases did not do justice to the policy importance of these population interventions.

Another participant speculated that if Lee had not assumed perfect foresight in his paper, perhaps the values of the externalities he had estimated would have been larger. The foresight assumption seemed counterintuitive in the context of fertility decisions. On incentives, the participant noted that altering the structure of relative prices between different contraceptives also created incentives within

This session was chaired by Carmen Miró, director of the Institute of National Studies at the University of Panama, Panama City.

두 1991 The International Bank for Reconstruction and Development / THE WORLD BANK. 
which contraceptive prevalence could be maintained at a lower family planning budget. He cited the example of Thailand for such a policy.

A participant, commenting on the Ammanpettai program, said that the program's founders had thought that its main effect would be to "condition" people to accept contraception by providing monetary incentives. However, it had far exceeded their expectations by serving as an excellent marketing and educational device, giving married women less than thirty-five years old an opportunity to hear about and try contraception and to overcome hesitation and fear. Whether such programs would work in areas of Africa where pronatalist tradition is strong is another matter, however.

A participant noted that many of the externalities cited in the Lee paper were not typically the ones considered by policymakers in framing population policies. For example, externalities relating to foreign aid did not seem to be very relevant.

A World Bank participant raised the issue of the difficulty of evaluating incentives programs because what is measured is almost always the acceptance of contraceptives and not the end impact of the incentives on fertility. There are also myriad stories about the effects of incentives in producing windfall claimants-for example, women accepting sterilization who weren't going to have more children anyway. Thus, acceptance rates can be highly misleading, especially in the presence of incentives. He also made the point that the Lee paper tended to mix externalities and income distribution questions. Parents do not consider the wage-depressing effect on the future labor force of having an additional child. The impact of an additional child here is not an externality, just as growing more wheat and depressing wheat prices is not an externality. So, the debate in the context of population growth is generally not about pure externalities but about redistributing future wealth and income.

In response to this participant, Lee clarified that his paper is concerned with only one among a large set of reasons for programs that went beyond family planning. He agreed with the need to keep pure externalities and distributional issues separate. Lee stood by his paper's conclusion, which Ainsworth (discussant) had considered too strong, that given the current state of research, externalities to childbearing do not provide a convincing rationale for fertility policies involving financial incentives or forms of coercion. He cautioned readers not to interpret his paper simplistically to mean that countries that were attempting to control population growth must be facing negative externalities associated with population growth, and vice versa. Regarding the comment about perfect foresight, Lee agreed that it was not a very good assumption, as he had himself pointed out in the paper; furthermore, the paper noted that the lack of foresight and information created a role for government educational programs.

Lee reiterated his paper's conclusion that with our present state of knowledge, it did not appear that high fertility in developing countries came about because of the existence of externalities that did not have to be borne by parents and were passed on to society. What then explained the pervasive sense that fertility 
is too high-inefficiently high? Lee opined that high fertility in developing countries reflected inefficient or missing markets-for insurance, for example-and inadequate public sector institutions. Because of these deficiencies, children represent the only viable form of old age security.

Chomitz said that their paper, contrary to Makinwa-Adebusoye's (discussant) comment, did not make a general and strong case for incentives. Rather, the paper's message was that there was a potentially strong case for incentives, but there was an equally strong case against them. The policy analyst's job was to determine what makes sense in a particular context. Chomitz argued that costbenefit calculations of incentive programs were feasible, important, and very inexpensive compared with the overall program costs, particularly if programs were set up so that they generated variation in the data.

Chomitz agreed with the comment that incentive schemes have to evaluated in terms of their effects on fertility as such, and not acceptance rates. He also found the suggestion intriguing that incentives were necessary to cover poststerilization medical costs-a sort of insurance scheme. Regarding the comment that incentive schemes would be misfiring if they provoked a rise in sterilizations during hard times, Chomitz said that he and Birdsall had suggested in their paper that any blip in payment acceptances during such times would be a cause for concern.

Carmen Miró (chair) ended the session by noting that both the topics of externalities and incentives were not likely to be resolved in the near future and will continue to be discussed for some time. 
